\title{
Valorization of Agricultural Residues for Cellulose Nanofibrils Production and Their Use in Nanocomposite Manufacturing
}

\author{
Ramzi Khiari ${ }^{1,2,3}$ \\ ${ }^{1}$ Higher Institute of Technological Studies of Ksar Hellal, Department of Textile, Ksar Hellal, Tunisia \\ ${ }^{2}$ University of Monastir, Faculty of Sciences, UR13ES63-Research Unity of Applied Chemistry \& Environment, 5000 Monastir, Tunisia \\ ${ }^{3}$ Université Grenoble Alpes, CNRS, Grenoble INP, LGP2, 38000 Grenoble, France
}

Correspondence should be addressed to Ramzi Khiari; khiari_ramzi2000@yahoo.fr

Received 9 March 2017; Revised 3 April 2017; Accepted 6 April 2017; Published 23 April 2017

Academic Editor: Qinglin Wu

Copyright (c) 2017 Ramzi Khiari. This is an open access article distributed under the Creative Commons Attribution License, which permits unrestricted use, distribution, and reproduction in any medium, provided the original work is properly cited.

\begin{abstract}
This paper reports the isolation of cellulose nanofibrils (CNFs) from almond stems, available as agricultural residues. The CNF suspensions were prepared by the combination of chemical and mechanical treatment: the microscopic fibres were firstly isolated by the delignification-bleaching process, followed by TEMPO-mediated oxidation to facilitate the further nanofibrillation using highpressure homogenization process at 600 bar for 10 passes as a mechanical treatment. The ensuing CNFs were characterized by several methods, such as transmission electron microscopy (TEM), degree of fibrillation, and carboxyl content. Different nanocomposites were prepared by casting-evaporation method from the mixture of CNF suspension in the commercial acrylic latex as a matrix. The effect of CNF loading on mechanical and thermal properties of the composites was then studied. The considerable enhancement of both Young's modulus and tensile strength was observed, which clearly indicates that the nanocomposites reinforced with the nanofibrils from Prunus amygdalus have promising mechanical properties.
\end{abstract}

\section{Introduction}

After the first discovery of extracted cellulose from plant by Anselme Payen in 1838, the cellulose science developed rapidly [1]. In 1870, the first type of cellulose derivatives, namely, celluloid, was successfully produced on an industrial scale by the Hyatt Manufacturing Company. Since then, cellulose extracted from wood species became an important raw material for industries. From 1920s, with the development of analytical chemistry and instrumentation, especially the development of X-ray diffraction (XRD) technique, many researchers have got much more information about cellulose, for example, morphology of cellulose at much smaller scale and structure of cellulose. During the period between 1940s and 1960s, using scanning electron microscopy (SEM) and XRD for studying the hydrolysed cellulose, scientists consequently investigated the crystalline structure of cellulose from various resources. In 1947, Nickerson and Habrle [2] was the first who employed hydrochloric $(\mathrm{HCl})$ and sulfuric $\left(\mathrm{H}_{2} \mathrm{SO}_{4}\right)$ acid hydrolysis to produce cellulose nanocrystals from cellulose materials. This innovative research on nanocellulose gave rise to investigations by the other researchers due to its ready availability, biodegradability, and biocompatibility. When it is interwoven, nanocellulose can form highly porous and mechanically strong bulk materials such as nanocellulose papers, films, or aerogels $[3,4]$.

In recent years, nanocellulose has been attracting much attention as a new bio-based nanomaterial with excellent properties [5-12]. As reported Mariano et al. [13], nanocellulose is classified in three subcategories (based on the source, preparation methodology, morphology, crystallinity, etc.). In general, cellulose nanomaterials can be categorized based on their morphology as follows: (i) CNFs, a "spaghetti-shaped" elongated fibrils prepared from wood and/or others natural cellulose sources using chemical and/or mechanical treatments, (ii) CNCs, a "rice-shaped" crystalline form prepared via acid hydrolysis of plant-, animal-, or bacteria-originated cellulose, and (iii) BNC, a web-like form of nanocellulose produced by bacteria or genetically transformed algae [10]. Nanocellulose can be extracted from diverse sources, including wood, cotton, grass, algae, bacteria, municipal solid waste, and even animals, such as tunicates. Thereby, nanocellulose 
receives considerable attention due to optical properties, high strength, large surface area, and sustainable raw material origin [14]. CNFs have been the subject of intense research activities, as summarized recently by Nechyporchuk et al. [15]. This is a promising natural nanostructured polymer to be used for different industries, for instance, in biomedical applications [11] or in various products as a rheology modifier [8]. Since 1980s, when Turbak et al. [16] reported the preparation of CNFs from wood fibres in water suspension using highpressure homogenization, an exponential number of scientific works has been published devoted to the isolation and characterization of CNFs using high-pressure homogenizers, microfluidizers, ultrafine friction grinders, extrusion, ball milling, cryocrushing, and ultrasonic method [14]. During all these processes, high energy consumption is required. Many researchers have focused on the exploration of new costeffective methods of CNFs production and their applications using various agricultural crops and residues or nonwood sources, such as wheat straw and soy hulls [17], sugar beet pulp [18], potato pulp [19], swede root [20], bagasse [21], sisal [22], algae [23], stems of cacti [24], banana rachis [25], and Posidonia oceanica $[6,8]$. The same strategy could be also applied for many Tunisian cellulosic residues, like Prunus amygdalus stems.

Prunus amygdalus is an agricultural residue, known as almond plants, and produced mainly in USA, Spain, Iran, Syria, Italy, Morocco, Turkey, and Tunisia with an amount of about 2 million tons as of 2014 (FAOSTAT data). According to FAO (FAOSTAT data), Tunisia is a producing country of Prunus amygdalus with $3.8 \%$ capacity. In Tunisia, this plant occupies about 194620 hectares (FAOSTAT data, 2014). To the best of our knowledge, no complete data about the preparation of CNFs from Prunus amygdalus residues is available in the literature. Therefore, this study focuses on the isolation and characterizing the CNFs produced from Prunus amygdalus residue stems. First, the microscopic cellulosic fibres were isolated from agricultural residues and then different CNF suspensions were prepared by 2,2,6,6tetramethylpiperidine-1-oxyl- (TEMPO-) mediated oxidation to facilitate the further nanofibrillation during homogenization process. The ensuing CNFs were used to prepare nanocomposites with latex matrix.

\section{Materials and Methods}

2.1. Raw Material: Prunus amygdalus and Reagents. Prunus amygdalus stem residues were obtained from Monastir, Tunisia, in July 2015 and dried under natural conditions. The agricultural residues were washed with water several times in order to eliminate sand and then were air-dried. Before pulping step, the Prunus amygdalus stem were cut into small pieces with lengths of about $1-3 \mathrm{~cm}$ in order to make easy the extraction of fibres. All chemicals and reagents utilized during this study were purchased from Sigma-Aldrich and were used without further purification. Commercial latex was kindly provided by MPC-Prokim (Tunisia). It was obtained by the copolymerization of styrene (S) (50 wt \%) and butyl acrylate (BA) (50 wt \%) resulting in poly(S-co-BA).
2.2. Isolation and Characterization of Fibres from Prunus amygdalus. Soda-anthraquinone cooking is considered as the most suitable process for pulping annual plants $[1,26]$ which is suggested during this study. The pulping of Prunus amygdalus was carried out according to a method derived from that described by Khiari et al. [26]. The procedure was performed in two steps. Briefly, during the first step, $16 \mathrm{~g}$ of Prunus amygdalus was cooked at $160^{\circ} \mathrm{C}$, with a total alkali charge of $20 \%$ expressed in $\mathrm{NaOH}$ (w/w, based on oven dried (o.d.) material), an anthraquinone concentration of $0.1 \%$ (w/w, with respect to o.d. material), and a cooking time of $120 \mathrm{~min}$. The resulting fibres were then washed extensively with water until a neutral $\mathrm{pH}$ was acquired. Finally, the fibres were dried (under atmospheric conditions: $25^{\circ} \mathrm{C}$ and $50 \% \mathrm{RH}$ (relative humidity)). The second step consisted of bleaching treatment. The fibres were bleached using a sodium chlorite $\left(\mathrm{NaClO}_{2}\right)$ solution in a buffer medium under mechanical stirring according to the well-established method of Wise et al. [27]. The delignification-bleaching protocol was carried out at least in duplicate and the difference between the obtained yields was within an experimental error of $5 \%$.

2.3. Preparation of CNFs from Prunus amygdalus. The CNF suspensions were produced from Prunus amygdalus using the same procedure as reported earlier by Bettaieb et al. $[6,8]$. The preparation of CNFs was accomplished in two steps. Briefly, the cellulose fibres were subjected to TEMPOmediated oxidation. About $5 \mathrm{~g}$ of pulp from Prunus amygdalus was dispersed in $500 \mathrm{~mL}$ of sodium phosphate buffer $\left(0.05 \mathrm{~mol} \cdot \mathrm{L}^{-1}, \mathrm{pH} 7\right)$ containing $25 \mathrm{mg}$ of TEMPO and $250 \mathrm{mg}$ of sodium bromide. Then, $1.13 \mathrm{~g}$ of sodium chlorite $(80 \%)$ and $2 \mathrm{~mol} \cdot \mathrm{L}^{-1}$ of sodium hypochlorite solution $(1.0 \mathrm{mmol})$ were added and the suspension was left under magnetic stirring at $60^{\circ} \mathrm{C}$ during $6 \mathrm{~h}$. At the end of the oxidation reaction, $100 \mathrm{~mL}$ of ethanol was added and the obtained modified fibres were filtered and washed several time with deionized water.

After the chemical treatment, about 2 wt \% of fibre suspension was homogenized with a high-pressure homogenizer (NS1001L PANDA 2K-GEA) for 10 passes at 600 bar until the consistence of the fibres suspension turned into a gellike form. As described by Herrick et al. [28], when the temperature increases from $20^{\circ} \mathrm{C}$ to $70-80^{\circ} \mathrm{C}$, a better fibrillation could be accomplished; therefore, during our treatment and due to the exothermic character of the reaction, the temperature was kept at $70^{\circ} \mathrm{C}$.

2.4. Preparation of Nanocomposites. In order to show the impact of use of CNF to reinforcing the nanocomposites, different nanocomposites were prepared using CNF suspensions mixed with latex matrix (commercial latex of poly(styreneco-butyl acrylate)) in various loadings of CNFs, namely, 0,1 , $2,5,7,10$, and $15 \%$ (w/w with respect to the matrix). After stirring, the suspensions were degassed under vacuum, cast into Teflon moulds, and finally dried at ambient temperature for several days. The nanocomposites were conditioned for $24 \mathrm{~h}$ under controlled temperature $\left(23^{\circ} \mathrm{C}\right)$ and relative humidity (50\%). All the nanocomposite films were prepared in triplicate. 
2.5. Characterization. Several methods were used to characterize the raw materials and/or the prepared CNFs and/or their nanocomposite films.

2.5.1. Morphological Properties. The morphological properties of Prunus amygdalus fibres were investigated using scanning electron microscope (SEM, model Philips XL 30). The samples were placed on the aluminium stubs and heated in the oven at $60^{\circ} \mathrm{C}$. Test specimens were then gold-coated using a vacuum sputter coater (model SC 500) before the analysis. The thickness of the gold layer was ca. 0.01-0.1 $\mu \mathrm{m}$. The accelerating voltage was fixed at $15 \mathrm{kV}$. The extracted fibres from Prunus amygdalus were studied using a MORFI analyser. This technical instrument can be access to main parameters of the fibre such as length, width, and the percent of fine elements. The measurements were evaluated by image analysis of a diluted suspension in a transparent flat channel captured by a CCD video camera. The test was repeated at least in triplicate. Concerning the morphology of CNFs, the transmission electron microscopy (TEM) using JEOL 200CX apparatus at $80 \mathrm{kV}$ was performed in order to investigate the nanofibril size and distribution. About $0.5 \mu \mathrm{L}$ of CNF suspension was dripped using a Labnet micropipette onto a 300-mesh carbon coated formvar copper grid, and the water was allowed to evaporate. Additional drop of CNF suspension was added onto the respective grids to increase the amount of cellulose particles and the process was repeated several times.

2.5.2. X-Ray Diffraction Analysis. The crystallinity of the cellulosic materials was examined using an X-ray diffractometer (D8-Advance Bruker AXS GmbH) at room temperature with a monochromatic CuK $\alpha$ radiation source $(\lambda=0.154 \mathrm{~nm})$ in step-scan mode with a $2 \theta$ angle ranging from $5^{\circ}$ to $60^{\circ}$ with a step of 0.04 and a scanning time of $5.0 \mathrm{~min}$. The method of Segal et al. [29] was tracked to evaluate the crystallinity of the different prepared samples. The crystallinity index $C_{I}$ was determined based on the reflected intensity data following:

$$
C_{I}(\%)=100 \times\left(\frac{I_{002}-I_{\mathrm{am}}}{I_{002}}\right),
$$

where $I_{002}$ is the maximum intensity of the (002) lattice diffraction peak and $I_{\mathrm{am}}$ is the intensity scattered by the amorphous part of the sample. The diffraction peak for plane (002) is located at a diffraction angle around $2 \theta=22^{\circ}$ and the intensity scattered by the amorphous part is measured as the lowest intensity at a diffraction angle around $2 \theta=18^{\circ}$.

Furthermore, the average thickness of cellulose crystallites was estimated also from the X-ray diffraction patterns by using Scherrer's equation [30]:

$$
D_{h k l}=\frac{K \lambda}{\beta_{1 / 2} \cos \theta}
$$

where $D_{h k l}$ is the crystallite dimension in the direction normal to the $h k l$ family of lattice planes, $K$ is the correction factor and usually taken to be $0.9, \lambda$ is the radiation wavelength, $\theta$ is the diffraction angle, and $\beta_{1 / 2}$ is the peak width at half maximum intensity.
2.5.3. The Yield of Fibrillation and Carboxyl Content. The carboxyl content of oxidized fibres was determined by the conductimetric titration. The oxidized fibres were suspended into $15 \mathrm{~mL}$ of hydrochloric acid $\left(\mathrm{HCl}, 0.01 \mathrm{~mol} \cdot \mathrm{L}^{-1}\right)$ solutions. After $30 \mathrm{~min}$ of stirring, the suspension was titrated with a solution of sodium hydroxide $\left(\mathrm{NaOH}, 0.01 \mathrm{~mol} \cdot \mathrm{L}^{-1}\right)$. The titration curves presented two intersection points: strong acids $\left(V_{1}\right.$ corresponding to the excess of $\left.\mathrm{HCl}\right)$ and a weak acids ( $V_{2}$ associated with the carboxyl content). The carboxyl content was determined from the following equation:

$$
n(\mathrm{COOH})=0.01 \times\left(V_{2}-V_{1}\right) \times 0.01 \text {. }
$$

The titrations were repeated at least in duplicate and the difference between the values was within an experimental error of $5 \%$. The fibrillation yield was evaluated as described by Bettaieb et al. [6, 8]. In a few words, a dilute suspension having about $0.2 \%$ of solid content (Sc) was centrifuged at $4000 \mathrm{rpm}$ during 30 min to separate the CNFs (in supernatant fraction) from the nonfibrillated and/or partially fibrillated fibres (the sediment). The sediment fraction was dried at $105^{\circ} \mathrm{C}$ in a halogen desiccator until a constant weight. The yield of the nanofibrillated fibres was determined as follows:

Yield of fibraltion (\%)

$$
=100 \times\left(1-\frac{\text { weight of dried sediment }}{\text { weight of diluted sample } \times \mathrm{Sc} \%}\right) \text {, }
$$

where $\mathrm{Sc} \%$ is a solid content of the diluted dispersion sample. The measurement was repeated at least in duplicate and the difference between the various values was within an experimental error of $5 \%$.

2.5.4. Tensile Testing and Dynamic Mechanical Analysis. The mechanical properties of the nanocomposites prepared from CNFs and latex as a matrix were tested using the dynamic mechanical analysis (DMA). The measurements were carried out using an RSA 3 DMA apparatus from Rheometrics. The nanocomposite films were cut into the rectangular strips with dimensions of $30 \times 5 \mathrm{~mm}^{2}$. The thickness of the films was $0.4 \mathrm{~mm}$, as measured using calipers. The DMA measurements were performed under isochronal conditions at $1 \mathrm{~Hz}$, and the temperature scanning interval varied from -90 to $100^{\circ} \mathrm{C}$ at a heating rate of $2^{\circ} \mathrm{C} \mathrm{min}{ }^{-1}$. These measurements were repeated at least in triplicate. The tensile testing of the prepared nanocomposite films was investigated using RSA 2 spectrometer from Rheometrics working in a tensile mode. The elongation and stress at break, as well as Young's modulus, were determined. The sample dimensions were the same as for DMA measurements. Tensile measurements were replicated 5 times and the difference between the various values obtained was within an experimental error of $5 \%$.

\section{Results and Discussions}

3.1. Characterization of Raw Material: Prunus amygdalus. The chemical composition of Prunus amygdalus was determined in a previous study [31], which showed that it contains about $60 \%$ of holocellulose. This quantity is similar to that 

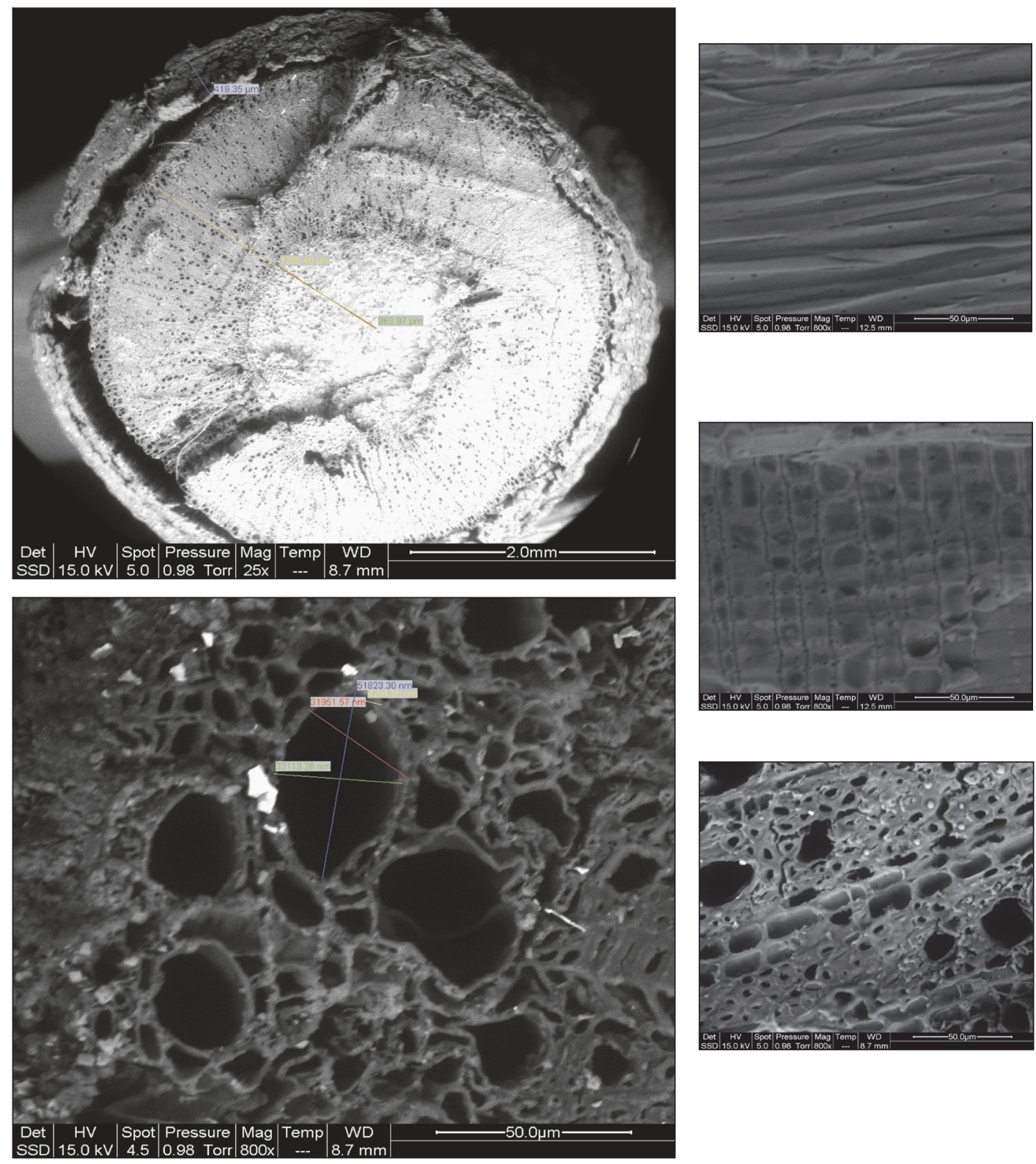

(a)

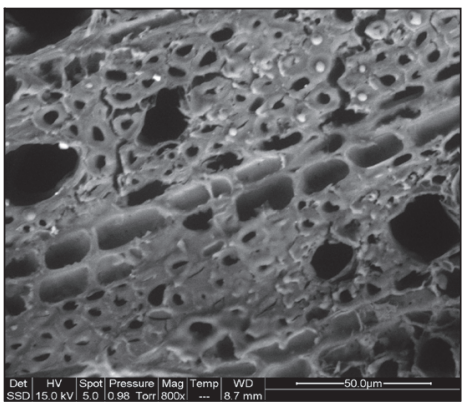

(b)

FIgUre 1: Macroscopic observation of the Prunus amygdalus: (a) cross section and (b) radial longitudinal section.

present in many other annual plants [32]. This raw material contains considerable amount of cellulose (i.e., 40\%), which justifies considering its valorization in cellulose derivatives field and/or as a source of fibres for papermaking applications or for cellulose fibre-reinforced composite materials.

In the current study, the morphological feature of this Tunisian agricultural residue is reported for the first time. The macroscopic appearance of Prunus amygdalus stem was examined with a scanning electron microscope at different magnifications. The morphology at surface, longitudinal views, and cross sections of the investigated raw materials are given in Figure 1. The deep analysis of obtained SEM images of Prunus amygdalus shows that the structure of this agricultural biomass is similar to that of the hardwood tree. The Prunus amygdalus stem is formed by a thin layer of living cells called vascular cambium that by repeated division produces phloem cells to the outside and secondary xylem (or wood) to the inside. The xylem can be divided into outer sapwood containing both living and dead cells and inner heartwood that is comprised entirely of dead cells where formation and deposition of phenolic compounds and other extractives have occurred, making heartwood less permeable and more durable. The Prunus amygdalus stem is composed mainly of sclereid cells (or fibres) with about $25 \mu \mathrm{m}$ in diameter and a wall having about $10 \mu \mathrm{m}$ of thickness. On the other hand, several different cell elements, namely, 


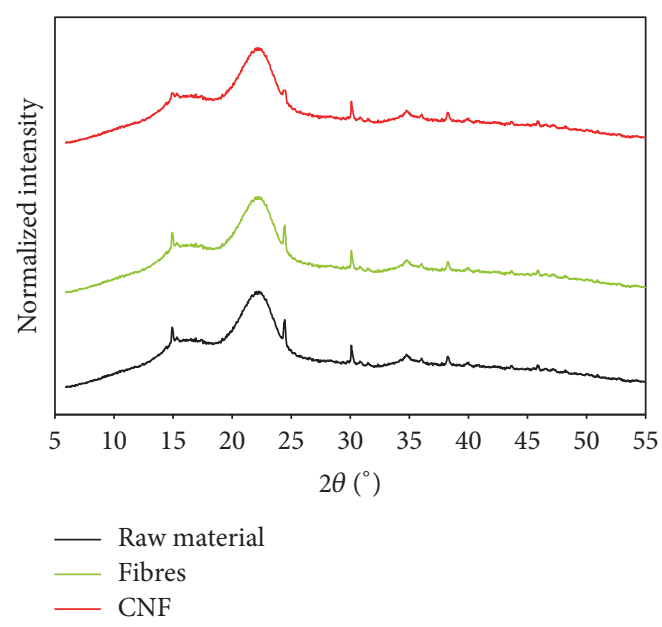

FIGURE 2: XRD pattern of Prunus amygdalus before pulping and their fibre and cellulose nanofibrils.

parenchyma, vascular tissue, epidermis, and the fibre cells can be seen in case.

For the analysis of the structure by XRD (Figure 2), typical cellulose I structure was examined in the diffraction pattern for each starting material. It has strong crystalline peaks at $16^{\circ}$ and $22^{\circ}$ corresponding to the (110) and (002) planes of crystals and weak crystalline peaks at $34.8^{\circ}$ to the (004) plane [33]. However, some mineral compounds were also detected, namely, silica $\left(\mathrm{SiO}_{2}\right)$ and weddellite $\left(\mathrm{CaC}_{2} \mathrm{O}_{4}\right.$ $2 \mathrm{H}_{2} \mathrm{O}$ ) which is a form of calcium oxalate. $C_{\mathrm{I}}$ was about $52 \%$. This value is comparable to those of other annual plants or agricultural crops $[26,31,34]$.

\subsection{Characterization of Fibres and Cellulose Nanofibrils} from Prunus amygdalus. Soda-anthraquinone pulping was performed in the reactor system equipped with a rotating mechanism consisting of 6 minireactors with a capacity of $1000 \mathrm{~mL}$ each. The cooking steep leading to pulping yielded around $45 \%$. The amount of yielded fibres appeared to be even better than that observed for the majority of annual plants and agricultural crops, generally around 35\% [26, 31, 32, 34]. The examination of the obtaining fibre from Prunus amygdalus (Figure 3 ) from the morphological point of view was studied using the MORFI and SEM techniques and the results are summarized in Table 1 and Figure 3.

Figure 3 shows that the width of the fibres obtained from Prunus amygdalus is close to that of the others isolated fibres from several annual plants such as Tamarisk sp., date palm, and Posidonia oceanica [26, 31]. While the average length $(0.49 \mathrm{~mm})$ is significantly lower compared to that of Astragalus armatus and Pituranthos chloranthus [34], Amaranthus caudatus L. [35], orache [35], Jerusalem artichoke [35], Stipagrostis pungens [36], Cannabis sativa [37], date palm rachis, and Posidonia oceanica [26]. These properties give consequently an aspect ratio of extracted Prunus amygdalus fibres of 20 , which is very low compared to softwood (i.e., 70) and hardwood (i.e., 50) fibres [38]. However, these values are similar to those established for the annual plants (which

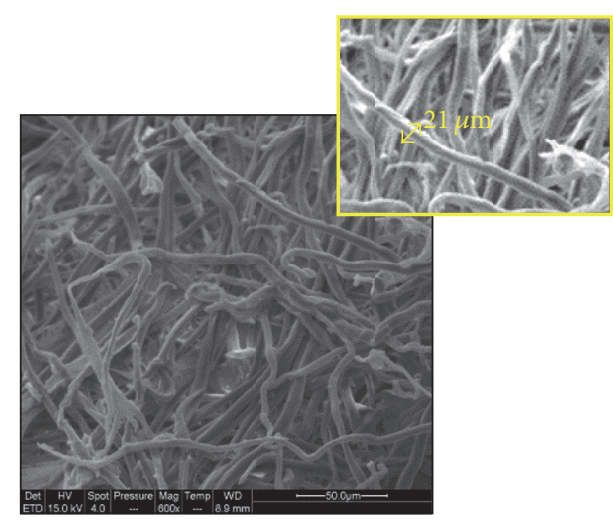

FIGURE 3: SEM image of Prunus amygdalus bleached pulp fibres.

are less than 50), for example, $P$. chloranthus and Tamarisk sp. pulp which are 16 and 21, respectively [34].

The overall conclusion to be deduced from this part, as well as that of the previously reported data, is that the residues obtained from Prunus amygdalus constitute a good cellulosic fibre when compared with other annual biomass [26, 32, 34, 38]. These large available residues can be seriously considered as an important cellulosic source for producing nanocellulose and their use in many fields, especially in nanocomposites. Thus, these are the objectives established in this paper and the results are described further.

As reported by several researches, $300 \mu \mathrm{mol} \mathrm{g}^{-1}$ of anionic groups is a minimal level in order to insure an effect on the fibrillation behaviour during the homogenization process [6, 14]. The fibres were submitted to TEMPO-mediated oxidation and the amount of the carboxyl content was up to about $500 \mu \mathrm{mol} \mathrm{g}^{-1}$. These oxidized fibres were then disintegrated in a high-pressure homogenizer for 10 passes. The amount of fibrillation was estimated to be $76 \%$. This value is near with that reported by Bettaieb et al. $[6,8]$, which was perceived in the case of CNF from Posidonia oceanica leaves and balls.

Figure 4 presents the TEM images of CNFs isolated from Prunus amygdalus stems. The first observations show that nanosized fibrils with wide distribution both in width and in length can be isolated. The dimensions of the CNFs were assessed by digital image analysis (Image J) of TEM micrographs using a minimum of 100 measurements. The analysis shows the successful isolation of CNFs with a width ranging from 3 to $18 \mathrm{~nm}$. It is important to mention that the individual fibrils with a width lower than $5 \mathrm{~nm}$ correspond presumably to elementary cellulose fibrils composed of altering crystalline and amorphous domains. Oppositely, in the case of the larger fibrils, they are likely composed of bundles of elementary fibrils bound together through hydrogen bonding.

The CNFs from Prunus amygdalus exhibit a typical aspect ratio of CNFs regardless of the cellulose source and the growth conditions [14], especially, when comparing these CNFs with those reported from potato pulp [19], algae [23], peel of prickly pear fruit [24], Opuntia ficus-indica, a cactus, swede root [20], hemp [39], rachis date palm [14], Posidonia oceanica balls $[6,8]$, and many others types of sources. In 
TABLE 1: The main properties of the pulps of Prunus amygdalus and others plants.

\begin{tabular}{|c|c|c|c|c|c|}
\hline & $\begin{array}{c}\text { Cooking yield } \\
(\%)\end{array}$ & $\begin{array}{c}\text { Screening yield } \\
(\%)\end{array}$ & $\begin{array}{l}\text { Fibre length } \\
(\mathrm{mm})\end{array}$ & $\begin{array}{l}\text { Fibre width } \\
\qquad(\mu \mathrm{m})\end{array}$ & $\begin{array}{c}\text { Fine elements } \\
\text { (\% in length) }\end{array}$ \\
\hline Prunus amygdalus (this work) & 45.2 & 95 & 0.48 & 21 & 24.3 \\
\hline Date palm rachis [26] & 44.8 & 94 & 0.89 & 22.3 & 30.8 \\
\hline P. oceanica balls [26] & 63.6 & 96 & 0.55 & 21.3 & 7.5 \\
\hline Tamarisk sp. [31] & 41.7 & 94 & 0.37 & 20 & 34.3 \\
\hline Astragalus armatus [34] & 32 & $* *$ & 0.811 & 20.6 & 17.1 \\
\hline Pituranthos chloranthus [34] & 37 & $* *$ & 0.58 & 22.9 & 28.5 \\
\hline Amaranthus caudatus L. [35] & 47 & 96 & 0.6 & $* *$ & $* *$ \\
\hline Orache [35] & 44.8 & 96 & 0.62 & $* *$ & $* *$ \\
\hline Jerusalem artichoke[35] & 35.2 & 96 & 0.9 & $* *$ & $* *$ \\
\hline Stipagrostis pungens [36] & 43 & $* *$ & 0.606 & 22.3 & 24.3 \\
\hline Cannabis sativa [37] & 55 & 98 & 1.8 & 29.5 & $* *$ \\
\hline Pinus radiata [38] & 55 & $* *$ & 1.9 & 31.6 & 7.4 \\
\hline Eucalyptus [38] & 50 & $* *$ & 0.77 & 20.9 & 12.2 \\
\hline
\end{tabular}

** Not available.
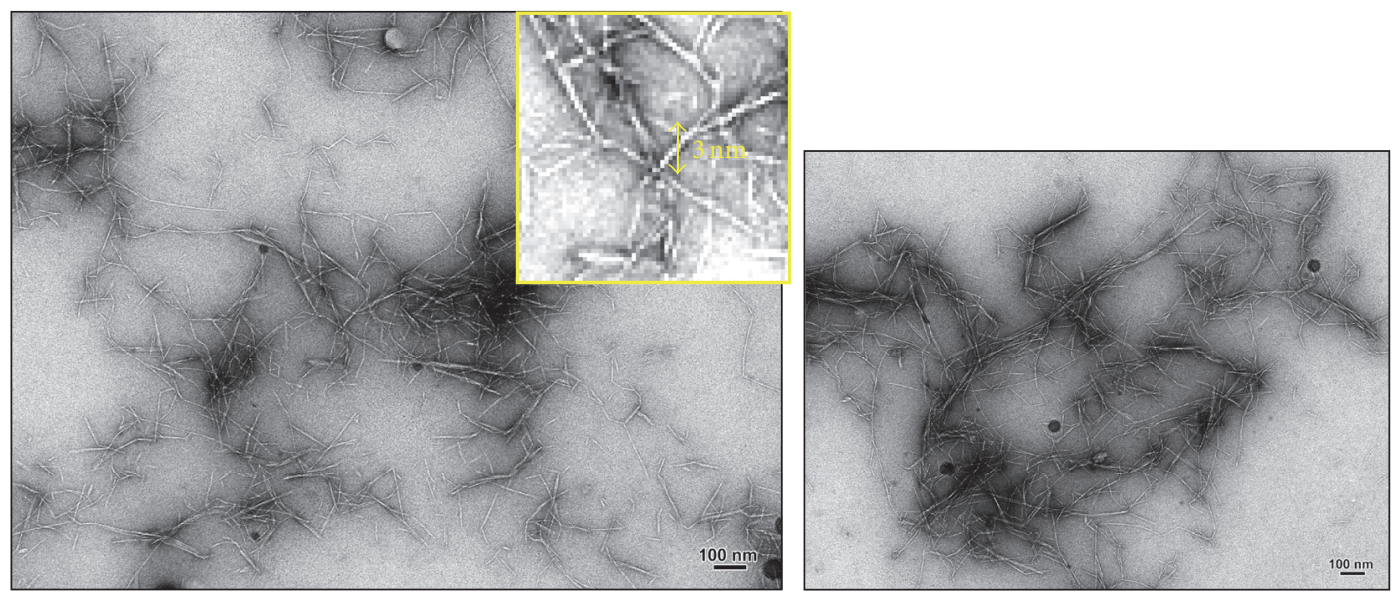

FIgURE 4: TEM observations of CNF from Prunus amygdalus.

all cases, the CNFs isolated from Prunus amygdalus indicate that these structures can be promising nanofibril as a filler for polymer matrixes, providing valorization of this worldwide produced agricultural waste. The analysis of CNFs and the fibres from Prunus amygdalus using XRD method shows a typical cellulose I structure (Figure 2). The crystallinity index was significantly increased from raw material to CNFs, which evolves from $52 \%$ to $78.8 \%$. The higher crystallinity index value can be well understood by the removal of amorphous noncellulosic compounds induced by the purification treatment (pulping and bleaching treatments) performed to purify cellulose stem. Furthermore, after the oxidation treatment, a part of the amorphous regions was removed. Consequently, the crystallinity of CNFs was further increased. The average cross-sectional dimension of the elementary cellulose crystallites was determined from X-ray diffractograms by applying Scherrer's expression as described in experimental section. Since Scherrer's equation is restricted to samples of high crystallinity and without any broadening of peaks, this calculation was made only for CNFs and the value of $7 \mathrm{~nm}$ was found.

\subsection{Preparation and Characterization of Nanocomposites.} The mechanical properties in terms of Young's modulus, strength, and elongation at break were evaluated at room temperature $\left(25^{\circ} \mathrm{C}\right)$ and the results are summarized in Table 2. The elongation at break decreased significantly with increasing the CNF loading due to the stiffening effect induced by the nanofiller [14], while the stress at break increases with CNF addition. It increased from $1.49 \mathrm{MPa}$ for the neat matrix to 16.62 MPa for the nanocomposite films with $15 \mathrm{wt}$. $\%$ of CNFs. Young's modulus is enhanced with increasing the nanofiller loading. For example, Young's modulus of the composite containing $15 \mathrm{wt} \%$ of Prunus amygdalus nanoparticles is 400 times higher than that of the unfilled matrix.

This data confirms again the importance of the use of nanocellulose for the nanocomposites application, since such features have been observed with CNFs from many other 
TABLE 2: Summary of mechanical properties for nanocomposites prepared from Prunus amygdalus CNFs.

\begin{tabular}{|c|c|c|c|c|c|}
\hline & \multicolumn{3}{|c|}{ Tensile testing } & \multicolumn{2}{|c|}{ DMA analysis } \\
\hline & Elongation at break (mm) & $E(\mathrm{MPa})$ & Stress at break $(\mathrm{MPa})$ & $E^{\prime}(\mathrm{MPa})$ at $70^{\circ} \mathrm{C}$ & $E_{r}=E_{c} / E_{\mathrm{mat}}$ \\
\hline Neat matrix & 3391 & 1.83 & 1.49 & 0.655 & 1.00 \\
\hline 1 wt.\% CNFs & 1562 & 109.1 & 2.74 & 2.578 & 3.93 \\
\hline 2 wt. $\%$ CNFs & 1443 & 162.3 & 4.48 & 36.528 & 55.74 \\
\hline 5 wt. $\%$ CNFs & 865 & 165.4 & 6.41 & 45.589 & 69.57 \\
\hline 7 wt.\% CNFs & 439 & 276.5 & 11.37 & 175.370 & 267.60 \\
\hline 10 wt.\% CNFs & 118 & 286.5 & 12.82 & 494.685 & 754.86 \\
\hline 15 wt.\% CNFs & 85 & 410.1 & 16.62 & 459.497 & 701.16 \\
\hline
\end{tabular}

$E$ : Young's modulus obtained by tensile test; $E^{\prime}$ (at $70^{\circ} \mathrm{C}$ ): Young's modulus obtained by DMA; $E_{r}$ : ratio of Young's modulus (DMA) of tested material by Young's modulus of neat matrix (DMA).

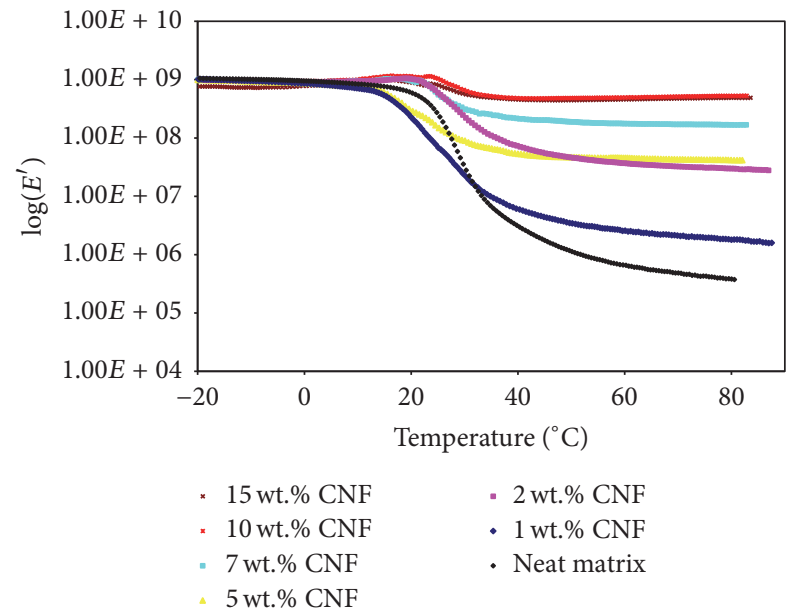

(a)

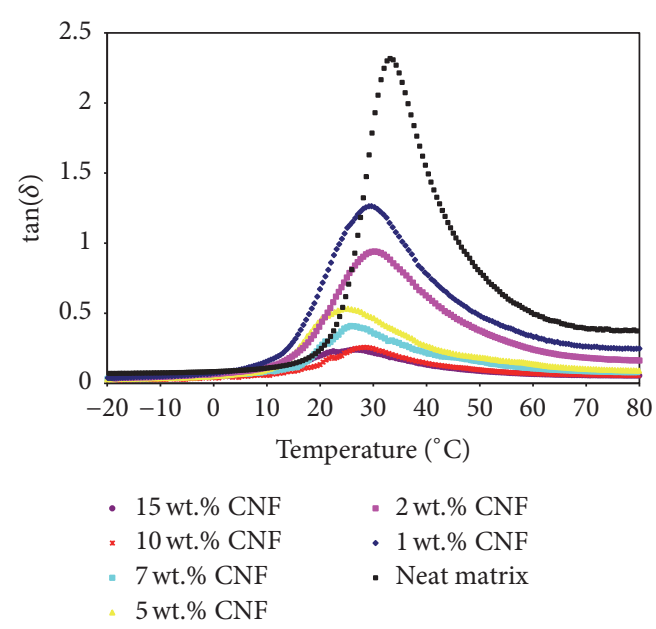

(b)

FIGURE 5: Evolution of (a) logarithm of storage tensile modulus $E^{\prime}$ and (b) loss angle $\tan (\delta)$ versus temperature at $1 \mathrm{~Hz}$ for nanocomposites based on CNFs derived from Prunus amygdalus.

sources, for example, potato pulp [19], algae [23], peel of prickly pear fruit [24] of Opuntia ficus-indica, a cactus, swede root [20], hemp [39], rachis date palm [14], and Posidonia oceanica $[6,8]$. Moreover, it can be noticed that the high reinforcing effect, in our case, is attributed to the formation of a stiff percolating nanofibrils network linked by strong hydrogen bonds between adjacent nanofibers and the physical entanglements of the flexible CNFs $[6,8,14]$. This reinforcement is common to cellulose-based nanofiller and is credited to the formation of a stiff percolation network.

The reinforcing potential of CNFs from Prunus amygdalus was also investigated by DMA. The evolution of the storage modulus $E^{\prime}$ as a function of temperature for different nanofiller loading is shown in Figure 5 for CNFs prepared from Prunus amygdalus. As expected, the effect of the inclusion of CNFs into the polymer matrix differs depending on the temperature range. From this figure, different conclusions can be taken: (i) below the glass transition temperature, no significant evolution in the storage modulus is detected upon the addition of CNFs; (ii) above the glass transition, the storage modulus is more susceptible to the presence of the nanofiller and is increased significantly with CNF addition, which is in line with the well-known reinforcing effect of cellulose-based nanofibrils $[6,8,14]$. This demonstrates clearly that the CNFs from Prunus amygdalus can act as an element limiting the mobility of the polymers chains above $\mathrm{Tg}$. The strong reinforcing potential above the glass transition is ascribed to the setup of a rigid entangled network formed by CNFs.

The resulting curve associated with the storage modulus $\left(E^{\prime}\right)$ for the unfilled commercial latex matrix (Figure 5(a)) displays a typical behaviour as that of fully amorphous thermoplastic polymers. Below the $\mathrm{Tg}$, that is, $30^{\circ} \mathrm{C}$, the neat matrix is in its glassy state with a storage modulus of about $1 \mathrm{GPa}$. It starts to decrease slightly with temperature but remains roughly constant. An abrupt and significant decrease is observed around $30^{\circ} \mathrm{C}$, corresponding to the relaxation behaviour associated with the transition of the matrix from glassy to rubbery states. In addition, for temperatures higher than the Tg of the matrix, the storage modulus attained a plateau-like stage around $1 \mathrm{MPa}$, which corresponds to a rubbery state.

Figure 5(a) shows the evolution of the $\log E^{\prime}$ curves of the nanocomposites films, which were normalized with respect to that of the neat matrix at the glassy plateau. Below the $\mathrm{Tg}$, there is no difference between the modulus values of 


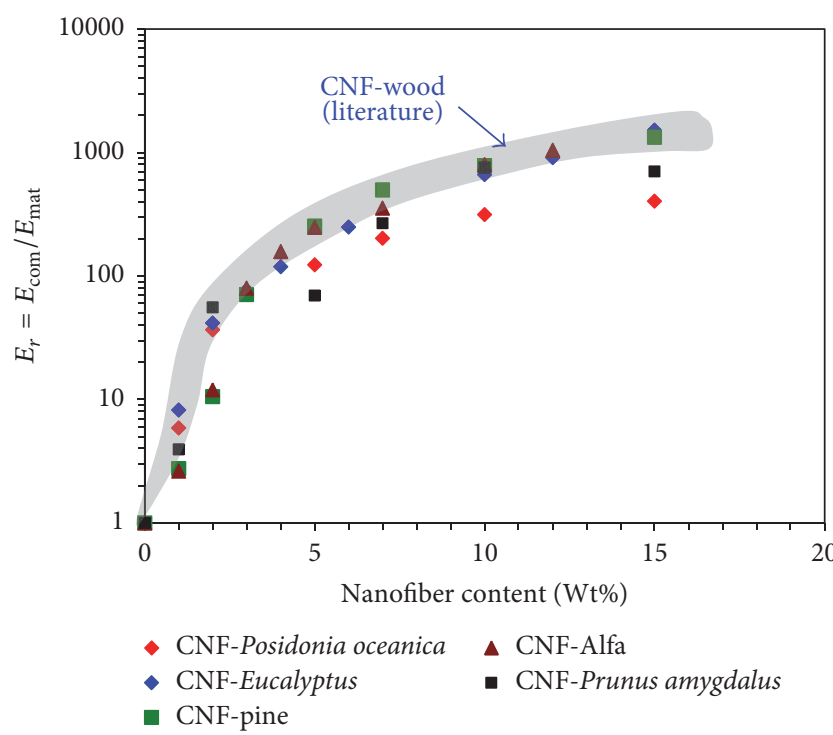

FIgURE 6: Evolution of the relative storage modulus $E_{r}=E_{c} / E_{\text {mat }}$ versus temperature at $1 \mathrm{~Hz}$ for nanocomposites based on CNFs at $70^{\circ} \mathrm{C}$.

the matrix and those of the filled composite films. However, above the $\mathrm{Tg}$, the presence of CNFs made a significant mechanical reinforcement. Indeed, the storage modulus of the nanocomposites containing $1,2,5,7,10$, and $15 \mathrm{wt} \%$ of CNFs from Prunus amygdalus (Table 2) were 2.6, 36.5, 45.6, $175.4,494.7$, and $459.5 \mathrm{MPa}$, respectively. Such increase is very significant when compared to that of the pure matrix $(0.655 \mathrm{MPa})$. Again, this behaviour is attributed to the incorporation of the CNFs from Prunus amygdalus nanofillers, which reinforced the matrix yielding homogeneous and continuous structure of the final nanocomposites films. This strong reinforcing potential can be explained by the setup of a rigid entangled network held through hydrogen interaction and physical entanglements in the bonded area [14].

Figure 5(b) shows the evolution of the $\tan (\delta)$ versus temperature at $1 \mathrm{~Hz}$ for the different nanocomposites based on CNFs. It can be remarked that the incorporation of the filler induced a decrease in the relaxation amplitude. This phenomenon can be attributed to the corresponding decrease of the entities participating in the relaxation mechanism.

Figure 6 illustrates the evolution of the storage modulus $E^{\prime}$ of the nanocomposites in the rubbery state (estimated at $70^{\circ} \mathrm{C}$ ) versus nanofiller content. This was traced in order to better emphasize the reinforcing effect of the different cellulosic nanofillers. From this figure, a significant rise in the storage modulus with nanofiller addition can be demonstrated. For instance, at $70^{\circ} \mathrm{C}$, the nanocomposites containing 1 and $15 \mathrm{wt} \% \mathrm{CNFs}$ exhibit a storage modulus of $2.6 \mathrm{MPa}$ and $459.5 \mathrm{MPa}$, respectively, which represents 4- and 700-fold improvement, respectively, with respect to that of the neat matrix $(0.655 \mathrm{MPa})$. The comparison from literature for nanocomposites prepared using acrylic matrixes and various CNFs from different sources such as wood and annual plant is also given here. It is important to mention that the same mixing route for nanocomposite films preparation was followed. Furthermore, the relative modulus extracted from the literature data was determined at the same temperature of $70^{\circ} \mathrm{C}$. It is interesting to note that, below $5 \% \mathrm{CNFs}$, the increment in the modulus was nearly similar to the nanocomposites prepared from wood-based CNFs. Though, above this content, the trend is different and the stiffening effect brought by the CNFs from Prunus amygdalus was slightly lower than that wood fibres. As accepted, this rationalized divergence can be attributed to the difference in the nanofibrils morphology, more specifically to the lower length of the cellulose nanofibrils from Prunus amygdalus compared to that from wood.

\section{Conclusion}

This paper describes the potential uses of lignocellulosic fibres obtained from an annual agricultural plant growing in large quantities in Tunisia. The morphological features of Prunus amygdalus stem was examined and described for the first time. This available residue from agricultural biomass was valorized to produce nanocellulose. The isolated fibres were investigated to produce CNFs, which showed good morphological properties. The distribution of the nanofibrils from Prunus amygdalus stem varied from 3 up to $18 \mathrm{~nm}$. These CNFs were further used as new nanofiller to prepare latex nanocomposites with high physical (thermal and mechanical) performance. The comparison in terms of mechanical behaviour of the ensuing nanocomposites with various CNF loading with other reported ones obtained from different plants showed that CNFs from the CNF from Prunus amygdalus were quite similar with the wood and had better properties than from Alfa and Posidonia oceanica. The unexploited residue of Prunus amygdalus can be considered as a serious alternative raw material, in order to prepare fibres and nanofibrils for high reinforcing potential when incorporated into a polymer matrix.

\section{Conflicts of Interest}

The author declares that there are no conflicts of interest regarding the publication of this paper.

\section{Acknowledgments}

The author gratefully expresses sincere gratitude to Professor Mohamed Naceur Belgacem, Professor Sami Boufi, Dr. Jean Luc Putaux, and Professor Alain Dufresne for her help and availability and to the "PHC-UTIQUE CMCU (Valorisation des Déchets Cellulosiques Tunisiens pour Produire des Matériaux Biosourcés et d'Emballage Fonctionnels, 13 G1114)" and "SSHN 2014 and SSHN 2016, L'Institut Français de Tunisie" for their financial support. In addition, the author would like to express sincere thanks to the Higher Education and Scientific Research in Tunisia and the project findings by Comite Mixte de Coopération Tuniso-Marocaine (Développement et Mise en CEuvre de Nouveaux Composites Verts à Partir des Ressources Renouvelables, 13/TM/24) and Comite Mixte de Coopération Tuniso-Egyptian (Preparation and Characterisation of Cellulosic Materials from Industrial 
and Natural Wastes. Applications in Textile, Composites, and Papermaking Industries).

\section{References}

[1] M. N. Belgacem and A. Gandini, Monomers, Polymers and Composites from Renewable Resources, Elsevier, Amsterdam, The Netherlands, 2008.

[2] R. F. Nickerson and J. A. Habrle, "Cellulose intercrystalline structure," Industrial \& Engineering Chemistry, vol. 39, no. 11, pp. 1507-1512, 1947.

[3] J. Cai, S. Liu, J. Feng et al., "Cellulosesilica nanocomposite aerogels by in situ formation of silica in cellulose gel," Angewandte Chemie, vol. 124, no. 9, pp. 2118-2121, 2012.

[4] H. Sehaqui, A. Liu, Q. Zhou, and L. A. Berglund, "Fast preparation procedure for large, flat cellulose and cellulose/inorganic nanopaper structures," Biomacromolecules, vol. 11, no. 9, pp. 2195-2198, 2010.

[5] F. Bettaieb, R. Khiari, A. Dufresne, M. F. Mhenni, and M. N. Belgacem, "Mechanical and thermal properties of Posidonia oceanica cellulose nanocrystal reinforced polymer," Carbohydrate Polymers, vol. 123, pp. 99-104, 2015.

[6] F. Bettaieb, R. Khiari, A. Dufresne, M. F. Mhenni, J. L. Putaux, and S. Boufi, "Nanofibrillar cellulose from Posidonia oceanica: Properties and morphological features," Industrial Crops and Products, vol. 72, pp. 97-106, 2015.

[7] F. Bettaieb, R. Khiari, M. L. Hassan et al., "Preparation and characterization of new cellulose nanocrystals from marine biomass Posidonia oceanica," Industrial Crops and Products, vol. 72, pp. 175-182, 2015.

[8] F. Bettaieb, O. Nechyporchuk, R. Khiari, M. F. Mhenni, A. Dufresne, and M. N. Belgacem, "Effect of the oxidation treatment on the production of cellulose nanofiber suspensions from Posidonia oceanica: the rheological aspect," Carbohydrate Polymers, vol. 134, pp. 664-672, 2015.

[9] F. Kallel, F. Bettaieb, R. Khiari, A. García, J. Bras, and S. E. Chaabouni, "Isolation and structural characterization of cellulose nanocrystals extracted from garlic straw residues," Industrial Crops and Products, vol. 87, pp. 287-296, 2016.

[10] D. Klemm, F. Kramer, S. Moritz et al., "Nanocelluloses: a new family of nature-based materials," Angewandte Chemie 2014-International Edition, vol. 50, no. 24, pp. 5438-5466, 2011.

[11] I. Siró and D. Plackett, "Microfibrillated cellulose and new nanocomposite materials: a review, Cellulose, vol. 17, no. 3, pp. 459-494, 2010.

[12] N. Lavoine, I. Desloges, A. Dufresne, and J. Bras, "Microfibrillated cellulose-its barrier properties and applications in cellulosic materials: a review," Carbohydrate Polymers, vol. 90, no. 2, pp. 735-764, 2012.

[13] M. Mariano, N. El Kissi, and A. Dufresne, "Cellulose nanocrystals and related nanocomposites: review of some properties and challenges," Journal of Polymer Science, Part B: Polymer Physics, vol. 52, no. 12, pp. 791-806, 2014.

[14] A. Dufresne, Nanocellulose: From Nature to High-Performance Tailored Materials, de Gruyter, Berlin, Germany, 2012.

[15] O. Nechyporchuk, M. N. Belgacem, and J. Bras, "Production of cellulose nanofibrils: a review of recent advances," Industrial Crops and Products, 2015.

[16] A. F. Turbak, F. W. Snyder, and K. R. Sandberg, "Microfibrillated cellulose, a new cellulose product: properties, uses, and commercial potential," Journal of Applied Polymer Science Applied Polymer Symposium, vol. 137, pp. 815-827, 1983.
[17] E. Espinosa, Q. Tarrés, M. Delgado-Aguilar, I. González, P. Mutjé, and A. Rodríguez, "Suitability of wheat straw semichemical pulp for the fabrication of lignocellulosic nanofibres and their application to papermaking slurries," Cellulose, vol. 23, no. 1, pp. 837-852, 2016.

[18] Y. Habibi and M. R. Vignon, "Optimization of cellouronic acid synthesis by TEMPO-mediated oxidation of cellulose III from sugar beet pulp," Cellulose, vol. 15, no. 1, pp. 177-185, 2008.

[19] A. Dufresne, D. Dupeyre, and M. R. Vignon, "Cellulose microfibrils from potato tuber cells: processing and characterization of starch-cellulose microfibril composites," Journal of Applied Polymer Science, vol. 76, no. 14, pp. 2080-2092, 2000.

[20] D. M. Bruce, R. N. Hobson, J. W. Farrent, and D. G. Hepworth, "High-performance composites from low-cost plant primary cell walls," Composites Part A: Applied Science and Manufacturing, vol. 36, no. 11, pp. 1486-1493, 2005.

[21] D. Bhattacharya, L. T. Germinario, and W. T. Winter, "Isolation, preparation and characterization of cellulose microfibers obtained from bagasse," Carbohydrate Polymers, vol. 73, no. 3, pp. 371-377, 2008.

[22] J. I. Morán, V. A. Alvarez, V. P. Cyras, and A. Vázquez, "Extraction of cellulose and preparation of nanocellulose from sisal fibers," Cellulose, vol. 15, no. 1, pp. 149-159, 2008.

[23] T. Imai, J.-L. Putaux, and J. Sugiyama, "Geometric phase analysis of lattice images from algal cellulose microfibrils," Polymer, vol. 44, no. 6, pp. 1871-1879, 2003.

[24] Y. Habibi, M. Mahrouz, and M. R. Vignon, "Microfibrillated cellulose from the peel of prickly pear fruits," Food Chemistry, vol. 115, no. 2, pp. 423-429, 2009.

[25] R. Zuluaga, J. L. Putaux, J. Cruz, J. Vélez, I. Mondragon, and P. Gañán, "Cellulose microfibrils from banana rachis: effect of alkaline treatments on structural and morphological features," Carbohydrate Polymers, vol. 76, no. 1, pp. 51-59, 2009.

[26] R. Khiari, M. F. Mhenni, M. N. Belgacem, and E. Mauret, "Chemical composition and pulping of date palm rachis and Posidonia oceanica-a comparison with other wood and nonwood fibre sources," Bioresource Technology, vol. 101, no. 2, pp. 775-780, 2010.

[27] L. E. Wise, M. Murphy, and A. A. D’Addieco, "Chlorite holocellulose: its fractionation and bearing on summative wood analysis and on studies on the hemicellulose," Paper Trade Journal, vol. 122, no. 2, pp. 35-43, 1946.

[28] F. W. Herrick, R. L. Casebier, J. K. Hamilton, and K. R. Sandberg, "Microfibrillated cellulose: morphology and accessibility," Journal oF Applied Polymer Science Applied Polymer Symposium, vol. 37, pp. 797-813, 1983.

[29] L. Segal, J. J. Creely, A. E. Martin, and C. M. Conrad, "An empirical method for estimating the degree of crystallinity of native cellulose using the x-ray diffractometer," Textile Research Journal, vol. 29, no. 10, pp. 786-794, 1959.

[30] H. P. Klug and L. E. Alexander, X-Ray Diffraction Procedures, John Wiley \& Sons, New York, NY, USA, 2nd edition, 1974.

[31] N. Mechi, R. Khiari, L. Ealoui, and M. N. Belgacem, "Preparation of paper sheet from cellulosic fibres obtained from Prunus amygdalus and Tamarisk sp," Cellulose Chemistry and Technology, vol. 7, no. 8, pp. 863-872, 2016.

[32] A. Antunes, E. Amaral, and M. N. Belgacem, "Cynara cardunculus L.: chemical composition and soda-anthraquinone cooking," Industrial Crops and Products, vol. 12, no. 2, pp. 8591, 2000.

[33] R. G. Liu, H. Yu, and Y. Huang, "Structure and morphology of cellulose in wheat straw," Cellulose, vol. 12, no. 1, pp. 25-34, 2005. 
[34] F. Ferhi, S. Das, E. Elaloui, Y. Moussaoui, and J. G. Yanez, "Chemical characterisation and suitability for papermaking applications studied on four species naturally growing in Tunisia," Industrial Crops and Products, vol. 61, pp. 180-185, 2014.

[35] M. Fiserova, J. Gigac, A. Majtnerova, and G. Szeiffova, "Evaluation of annual plants (AmaranthuscaudatusL., AtriplexHortensisL., HelianthusTuberosusL.) for pulp production," Cellulose Chemistry and Technology, vol. 40, no. 6, pp. 405-412, 2006.

[36] F. Ferhi, S. Das, Y. Moussaoui, E. Elaloui, and J. G. Yanez, "Paper from Stipagrostis pungens," Industrial Crops and Products, vol. 59, pp. 109-114, 2014.

[37] D. Dutt, J. S. Upadhyaya, C. H. Tyagi, A. Kumar, and M. Lal, "Studies on Ipomea carnea and Cannabis sativa as an alternative pulp blend for softwood: an optimization of kraft delignification process," Industrial Crops and Products, vol. 28, no. 2, pp. 128$136,2008$.

[38] S. Mansouri, R. Khiari, N. Bendouissa, S. Saadallah, F. Mhenni, and E. Mauret, "Chemical composition and pulp characterization of Tunisian vine stems," Industrial Crops and Products, vol. 36, no. 1, pp. 22-27, 2012.

[39] B. Wang and M. Sain, "Isolation of nanofibers from soybean source and their reinforcing capability on synthetic polymers," Composites Science and Technology, vol. 67, no. 11-12, pp. 25212527, 2007. 

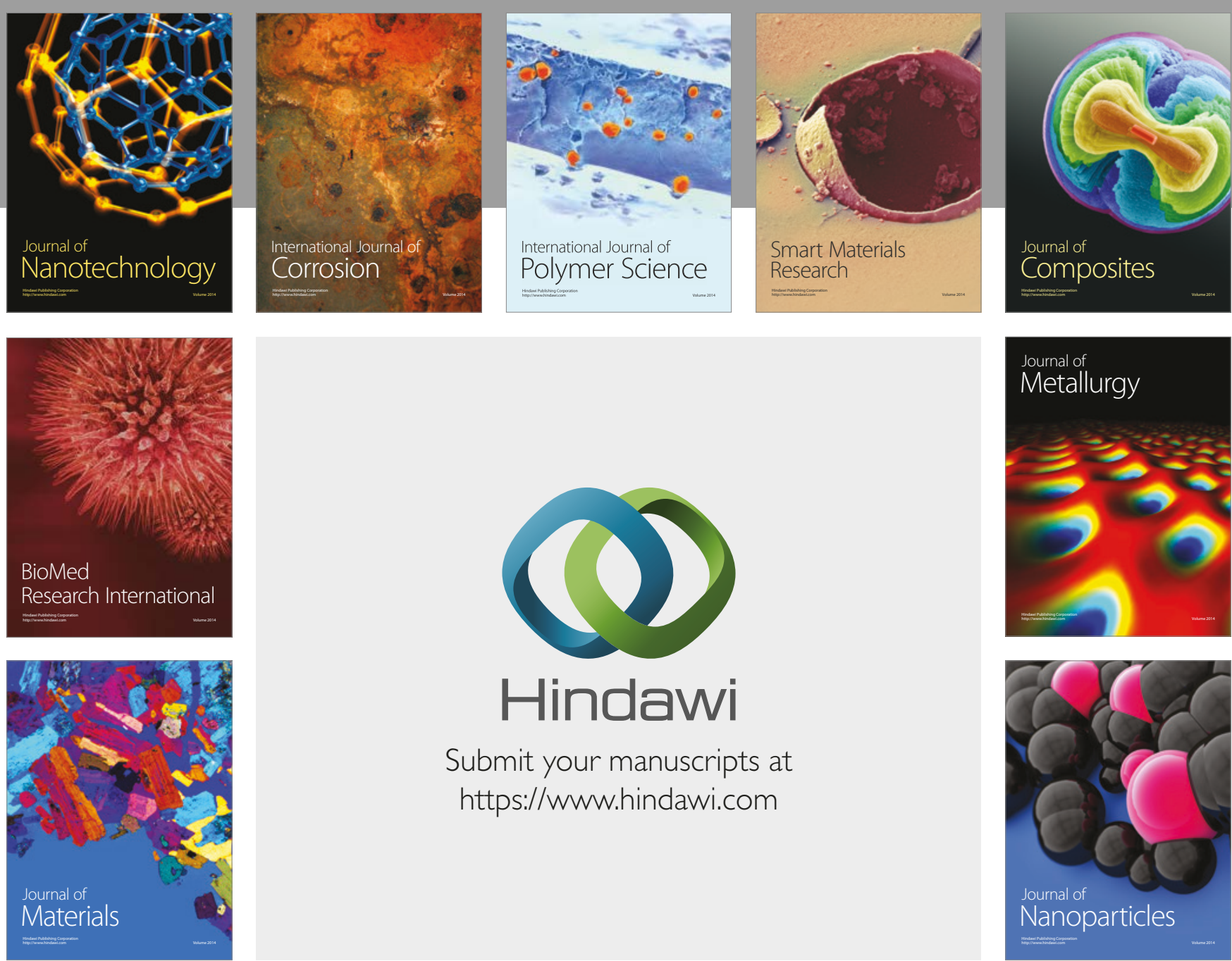

\section{Hindawi}

Submit your manuscripts at

https://www.hindawi.com
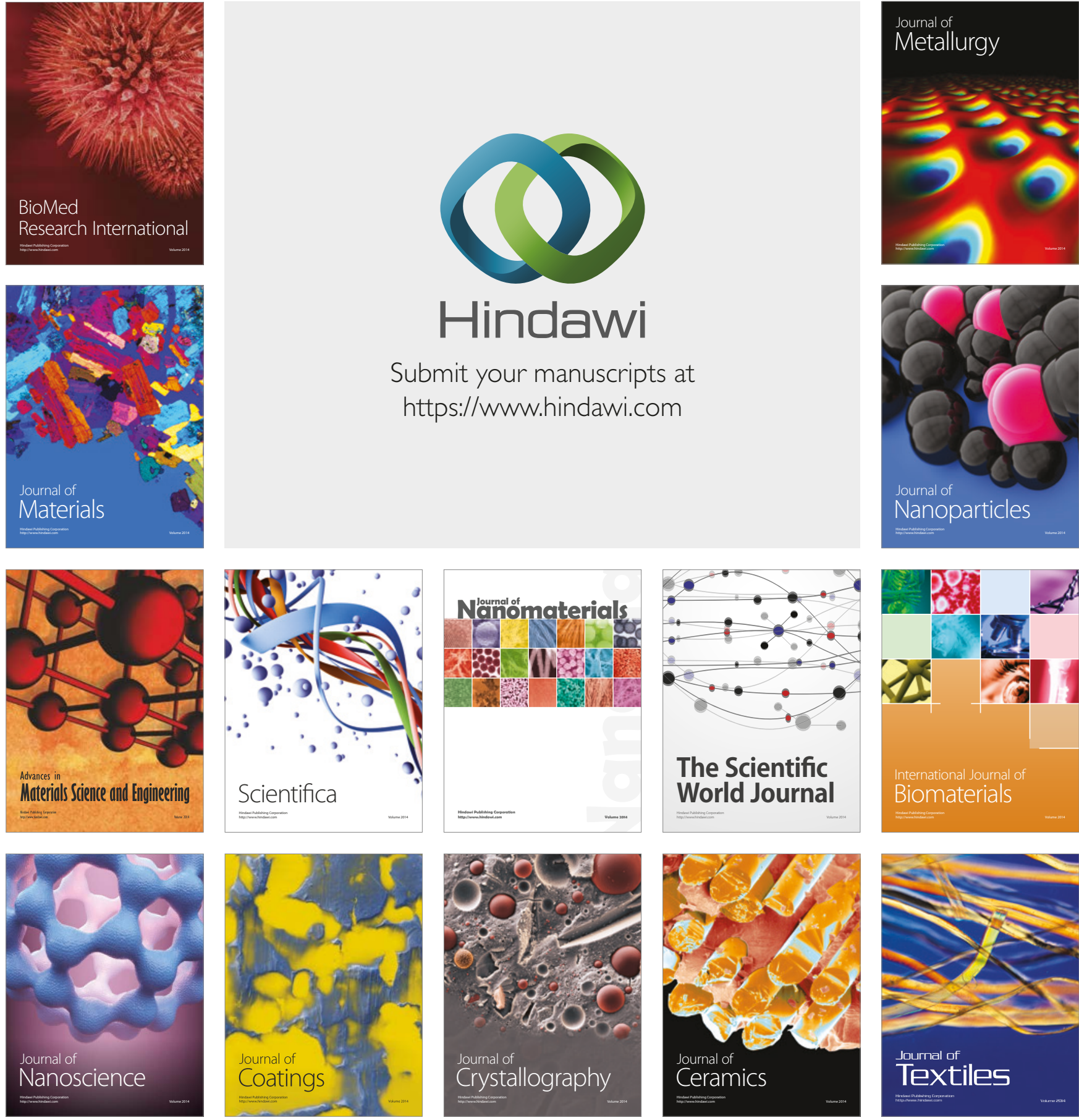

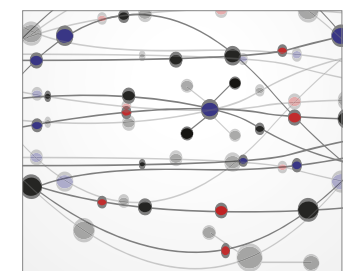

The Scientific World Journal
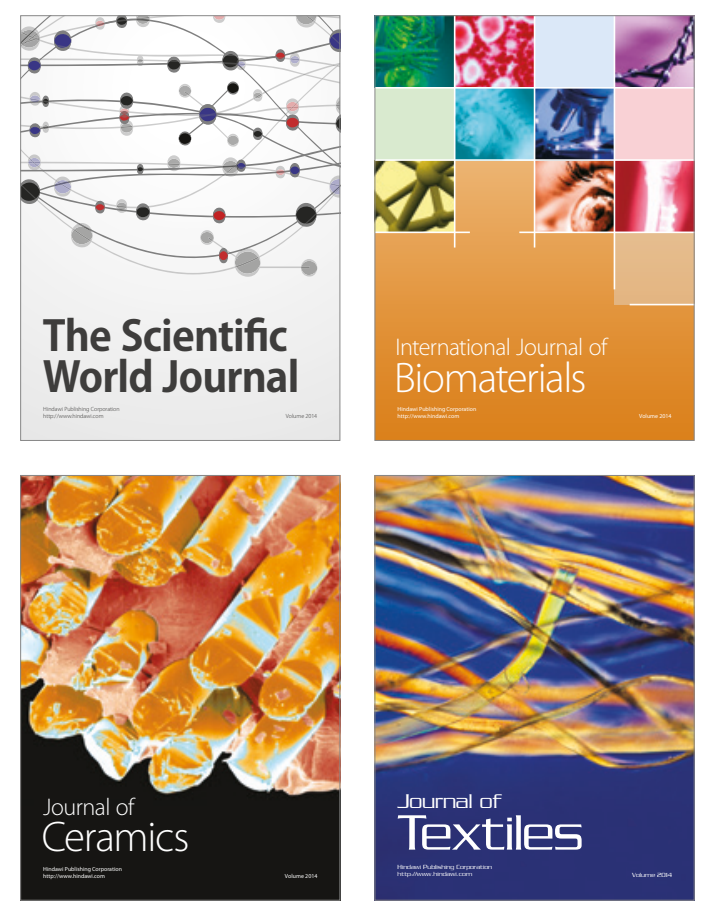